\title{
Crack Commencement and Transmissionan Alysison Heavy Vehicle Propeller Shaft by using Wavelet Transform
}

\author{
K.V.N.Varma ${ }^{1} \mid$ K.V.P.P.Chandu ${ }^{2} \mid$ K.Venkateswara Rao ${ }^{3}$
}

${ }^{1}$ PG Scholar, Department of Mechanical Engineering, Sir CR REDDY College of engineering, Eluru. ${ }^{2}$ Asst.Professor, Department of Mechanical Engineering, Sir CR REDDY College of engineering, Eluru. ${ }^{3}$ Professor, Department of Mechanical Engineering, Sir CR REDDY College of engineering, Eluru.

\section{To Cite this Article}

K.V.N.Varma, K.V.P.P.Chandu and K.Venkateswara Rao, "Crack Commencement and Transmissionan Alysison Heavy Vehicle Propeller Shaft by using Wavelet Transform", International Journal for Modern Trends in Science and Technology, Vol. 07, Issue 03, March 2021, pp.: 304-309.

\section{Article Info}

Received on 19-February-2021, Revised on 16-March-2021, Accepted on 22-March-2021, Published on 27-March-2021.

\section{ABSTRACT}

Present work gives an overview of cracks determination in material usingnatural frequency and wavelet transformation method and its application tocurrent engineering problems. In this technique, comparison between actualnatural frequency (without crack) and frequency due to crack propagation ismade using Euler Beam theory. When cracks are present in structure, natural frequency of material deviates from its original frequencyandresultdifference will measure in term of crack. Whole analysis procedure starting from modeling, meshing and resul tinterpretation done on well-known numerical tool ANSYS. The main aim of proposed study is to detect critical areas especially crack initiativezone before doing actual fabrication of components and avoid the breakage of it. Effects of a breathing crack on thevibratory characteristics of a rotating propeller shaft are investigated. Here three types of load consideration have taken such as axial, bending and torsionloadings. Results of numerical Finite Element Method (FEM) are validatedusingnumericalresultshasdoneusing MATLAB.

KEYWORDS: Stress intensity factor(SIF), modeling of drive shaft,crack initiation and elliptical crack.

\section{INTRODUCTION}

In machinery, cylindrical shaped components with a round cross section are used to operate. Bars, reinforcement, pins, shafts, wires, bolts or screws are some examples of cylindrical shaped structure. These structures are used in loading condition which is but complex. Usually engineering structures are designed to withstand the loads till the day of maintenance. Among these structures, beams are considered the most utilized structural components within various structural elements in in many applications in machinery and it experience sawide mixed bag of staticandelementloads.Formostofthe engineering applications, beams are widely used as components in engineering applications because it provides a fundamental model for various engineering applications. Some examples ofstructural components are helicopter rotor blades, Aircraft wings, spacecraft antenna, and robot arms etc, which might be modeled with beam like element. Beam like structures are generally usedinsteelshapedstructureandmanufacturing ofmachines.

\section{STRESSINTENSITYFACTOR (SIF)}

When the crack surfaces are displaced in the opening mode (ModeI), the Measurement of the 
stress field intensity near the tip of an ideal crack in alinear elastic solid is called as stress intensity factor. The stress intensity factors are used to interpret the singular stress or local stress and displacement field in the cracked tip. The SIF depends on the loading, the crack size, the crack shape,the geometric boundaries of the specimen.There commended units for $\mathrm{K}$ are $\mathrm{MPa} \sqrt{\mathrm{m}}$. it is customary to write the generalformula in the form $\mathrm{K}=\mathrm{Y} \sigma$ па where $\sigma$ is the applied stress, a is crack depth, $\mathrm{Y}$ is dimensionless shape factor.

\section{LITERATUREREVIEW}

Usually structures experiences a wide range of static and dynamic loads that suffers from damages.Due to this,its dynamic properties can change,especially the crack damage can cause are ductioninstiffness, withaninherent reduction in natural frequencies, and there will be change of mode shapes.In vibration analysis of cracked beams and shafts, generally the fracture mechanics procedure is preferred. In this procedure a crack that occurred in beam or shaft at crack location the local stiffness will reduce.Using second castigiliano's theorem that are applied in the facture mechanical formulation, the fracture mechanics mod 1 the local stiffness at crack locationwas found. Different researchers have in estigated the damages of cracks anditslocalizedeffects. They are summarizedbelow. Andrea Carpinteri [1] has theoretically proposed the Three-parameter fracturemechanics model to analyze the propagation of an elliptical-arc part-throughflaw in a round bar subjected to constant cyclic amplitude axial or bendingloads. The edge flaw presentsan aspect ratio and a relative crack depth.Additionally a parameter $\mathrm{s}=\mathrm{D} / \mathrm{a}$ (ellipse shifting) defines the distance of theellipsecenterfrom thebarcircumference. Aniket S.Kamble [2] has proposed a crack is modeled rotational spring and equation for non-dimensional spring stiffnessis developed.By calculating the first three natural frequencies using vibration measurements, curves of crackequivalent stiffness are plotted and the intersection of the three curves thatindicates the crack location and size. To obtain time frequency data and timeamplitudedata, wavelet analysis is performed. Main structural MarcoA.Perez[3] has presented to investigate the feasibility of using vibration-based methods to identify damages sustained by composite laminates due to low-velocityimpacts.Four damage indicators based on modal parameters were calculated by comparing pristineand damaged areas. It's accuracy is determined in the location of damage, its sensitivity in the damage extent and pertinent correlations with residual bearing capacity.

Three dimentional software called CATIA is used in this project . initially, CATIA named as an abbrivation for computer aided three dimentional interactive applications, the French Dassault Systems is the parent company, and CATIA is widely used in industrial sectors, and has been explained in theprevious post position of CATIA between $3 \mathrm{~d}$ modeling software.Before usingsketch select the plane of the CATIA display and then go to sketch. So thatgenerating of face can be done in CATIA. Draw the drawing which is having an accurate dimension then convert to three dimensional solid.

Propeller shaft is main component in the vehicle to transfer the engine torque to differential of vehicle.so maximum stresses can be induced and itcanfailure with propagation of crack. Here Ashok Leyland Truck model -6DT120 isselected to run the analysis.it having maximum power is $132 \mathrm{KW}$, Max torqueis $660 \mathrm{~N}-\mathrm{m}$,speed limit is 1200 to 1600 RPM.length of shaft is $1800 \mathrm{~mm}$, it was created in CATIA software and figureis shown below.

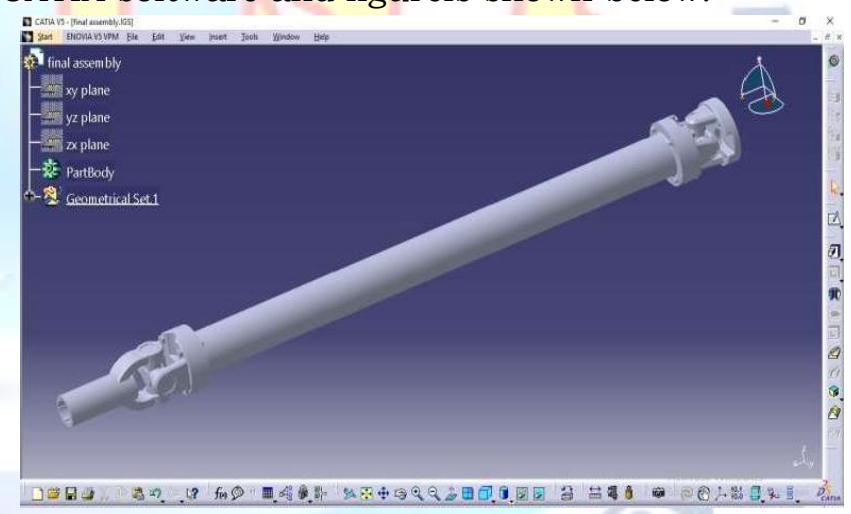

Fig 1:3D view of drive shaft.

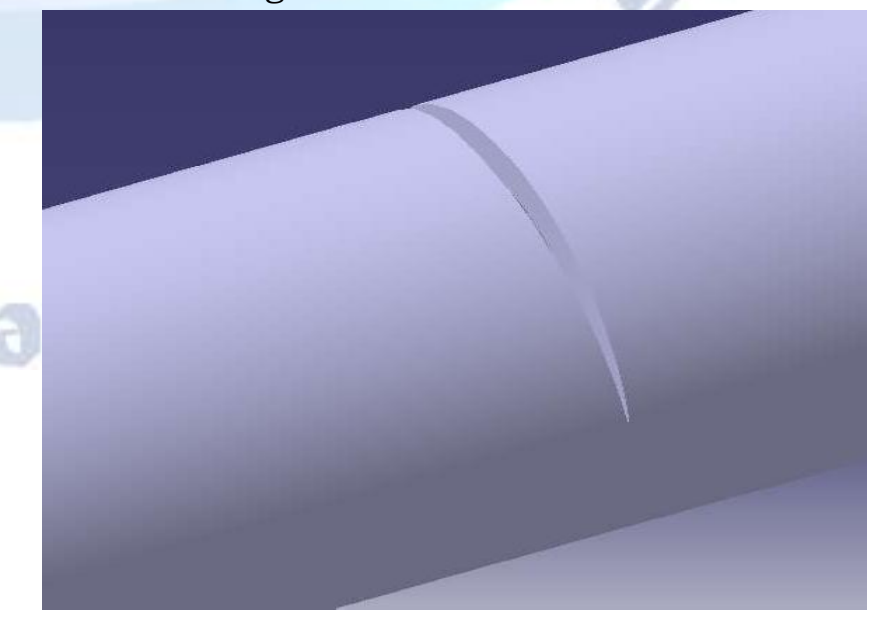

Fig2: crack created ondriveshaft. 
After creating the total sketch, axis line is created in sketch module. Using this, revolve option is used to apply on the shaft with the angleof 360 degree. From the reviewed article, the crack parameters are taken thatare created using surface module. Finally symmetric model is prepared usingCATIAsoftware. And the final model is saved in IGES format. To run the Analysis, 64 bit operating system, 4GB ram And ANSYS 19.0 isvery apt configuration to run analysis. The previously created IGS file fromCATIA is imported on ANSYS file geometry. Using ANSYS software, thestatic structure andmodal analysis is performed. The tabular column of different parameters and circular cross section of the different materials for different components is used bicycle seat assembly are shown below. Solidmesh 200 elements are used to divide the geometric body in to small strips using finite element method. The material used in the present work is Mild Steel and its structural properties are given in the table1.

\begin{tabular}{|c|c|}
\hline Parameters & Circularcross-sectionbeam \\
\hline Young'sModulus & $2.1 \square 10^{1} \mathrm{~N} / \mathrm{m}^{2}$ \\
\hline Density & $7850 \mathrm{~kg} / \mathrm{m}^{3}$ \\
\hline Poissonratio & 0.3 \\
\hline
\end{tabular}

Table1Material Properties of theShaft.

\section{CRACK INITIATION OF THE DRIVE SHAFT}

This work addresses the inverse method of fault detection in shaft part. One ofthe failures might be due to the crack initiation and propagation in any of the shaft part. natural frequency of shaft is calculated by Modal Analysis using the software ANSYS and MatLab.

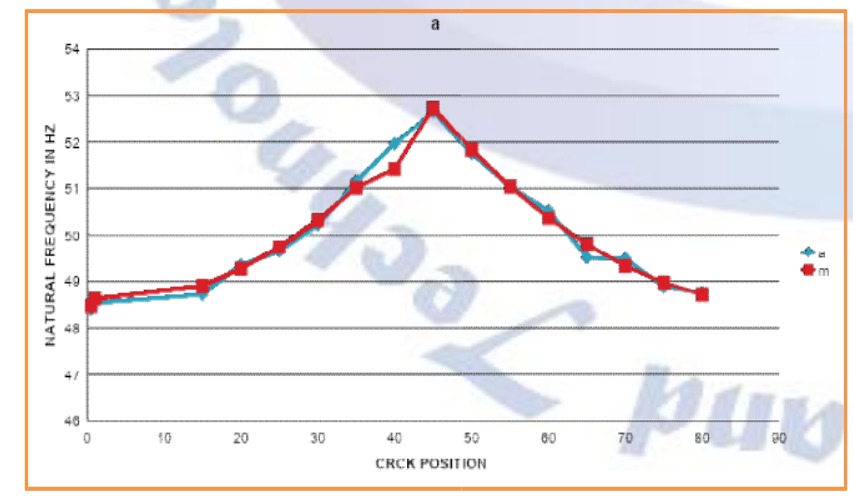

Graph1: natural frequency reading of drive shaft.

The above table shows the natural frequency reading of with andwithoutcrack shaft. Here to find out the crack initiation initially geometrical creakprovided on shaft at different locations on drive shaft and at $200 \mathrm{~mm}$ from thecenter having minimum natural frequency so further extension has carried outonsamelocation. Crack initation is analyzed using wavelet transformation. The Wavelet Transform is a mathematical process, in which a signal is analyzed using Asset of analyzing functions. Wavelet Transform belongs to the field of time-frequency analysis. The most well-known technique for frequency analysis is the Fourier transform. In the following figures crack had varied different locations of crack $(0.1,0.20,0.30,0.40$, $0.50,0.60,0.70,0.75,0.80)$ in driveshaft. In thefollowing figures we had taken values atd=depth (0.01)

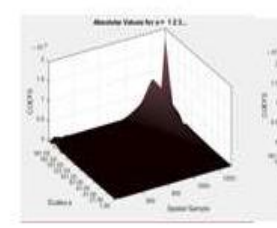

3 (a)

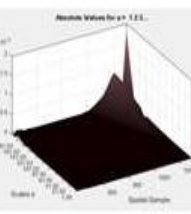

3 (b)

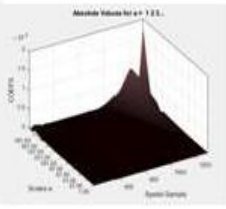

$3(\mathrm{c})$

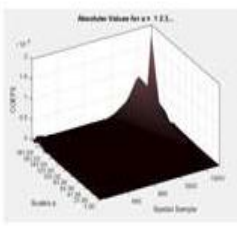

3 (d)

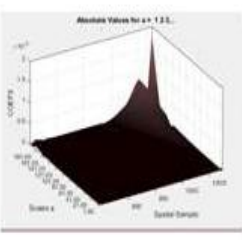

$3(\mathrm{~g})$

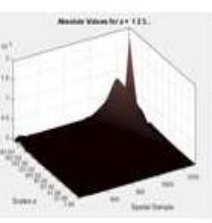

$3(\mathrm{e})$

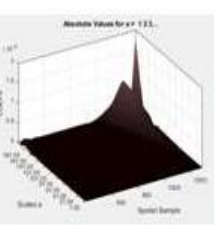

$3(\mathrm{~h})$

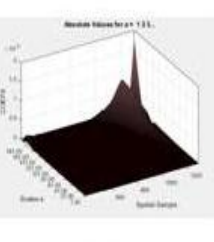

$3(f)$

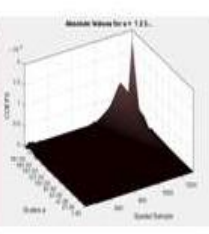

3(i)
From the above figure we had input wavelet signals into beam at different locations to identify the crack initial propagation but at depth 0.01 we observed every slightly variation at values, so we had increased depth ratio ofcrack in further analysis.As well as differentdepthof crack alsostudied inthis work. Tensile, bending and tensional load analysis has done on the propeller with changing the crack depth andlocation of crack. 


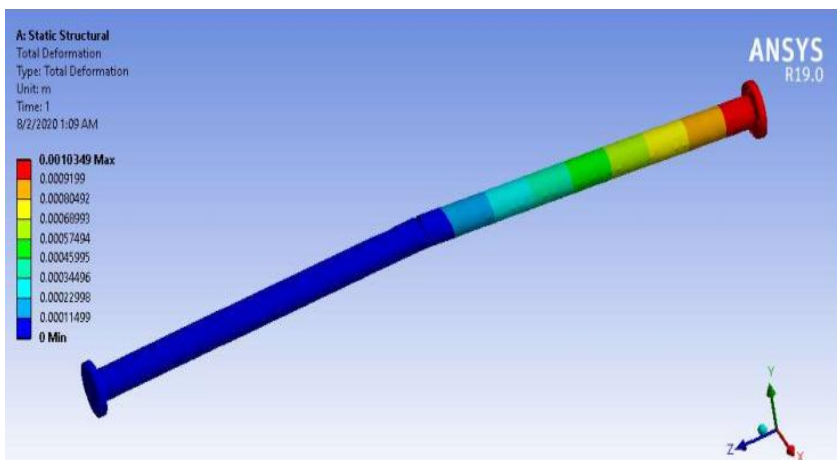

Fig: 4 deformation of propeller shaft at 0.9 depth ratio.

The above image shows the deformation of propeller shaft at 0.9 crack depth ratio. Here axial loading is applied at one end of drive shaft and another end is fixed at all degree of freedom.The red colo rindicates the maximum deformation and blue indicates the minimum deformation. $0.00103 \mathrm{~m}$ deformation is observed at free end of propeller shaft due to axial loading.

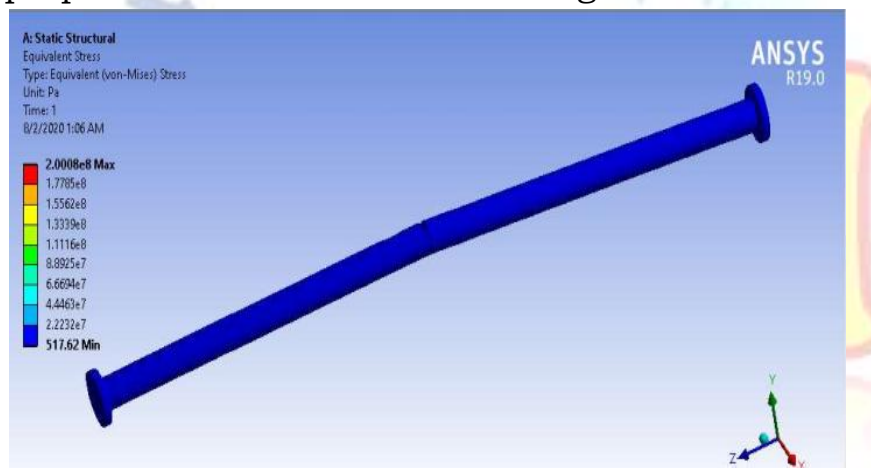

Fig: 5.Stress of propeller shaft at 0.9 depth ratio.

The above image shows the Stress of propeller shaft at 0.9 crack depth ratio.Here axial loading is applied at one end of drive shaft and another end is fixedat all degree of freedom. The red color indicates the maximum Stress and blueindicates the minimum Stress. 0.2 GPa Stress is observed at middle of propeller shaft due to axial loading.

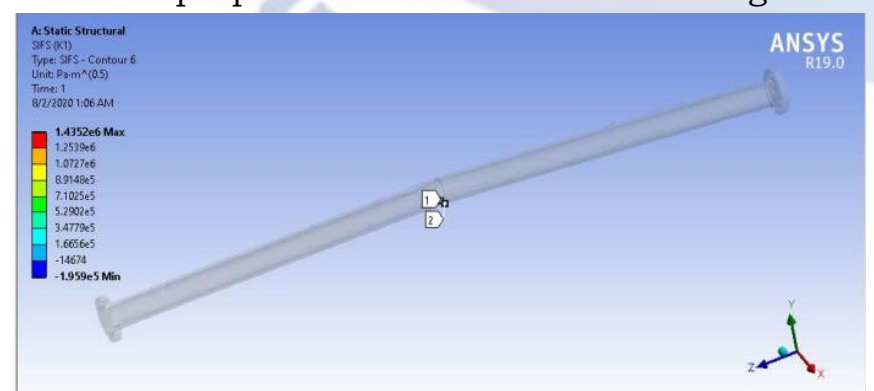

Fig: 6 SIF of propeller shaft at 0.9 depth ratio. The above image shows the SIF of propeller shaft at 0.9 crack depth ratio. Here axial loading is applied at one end of drive shaft and another end is fixed at all degree of freedom.1.9e5 $\mathrm{Pam}^{\wedge} 0.5 \mathrm{SIF}$ observed at the crack location.

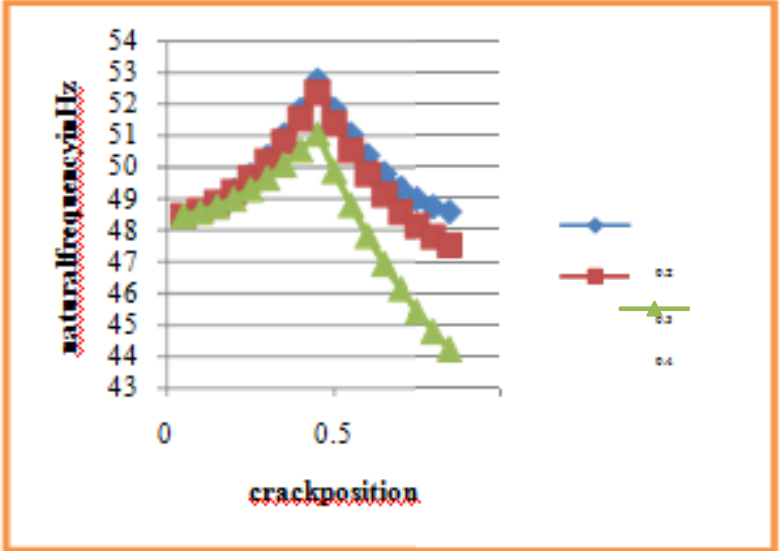

Graph:2 the average natural frequency of propellershaft with0.2,0.3,0.4crackdepth at different positions.

By taking average of all frequency of propeller shaft at different location, wehave increased crack depth also gradually, by this we able see the stiffness values was gradually decreasing from 0 to $1 \mathrm{crack}$ position, and we also observe while we increasing the crack depth the rate of damage is increasing.

\begin{tabular}{|c|c|c|}
\hline $\mathrm{c} / \mathrm{d}$ & $\begin{array}{c}\text { ANSYS } \\
\mathrm{Pa}\end{array}$ & $\begin{array}{c}\text { MATLAB } \\
\mathrm{Pa}\end{array}$ \\
\hline 0.2 & 77911 & 75706.05 \\
\hline 0.3 & 97441 & 92720.6 \\
\hline 0.4 & $1.13 \mathrm{E}+05$ & $1.07 \mathrm{E}+05$ \\
\hline 0.5 & $1.22 \mathrm{E}+05$ & $1.197 \mathrm{E}+05$ \\
\hline 0.6 & $1.30 \mathrm{E}+05$ & $1.31 \mathrm{E}+05$ \\
\hline 0.7 & $1.48 \mathrm{E}+05$ & $1.416 \mathrm{E}+05$ \\
\hline 0.8 & $1.60 \mathrm{E}+05$ & $1.514 \mathrm{E}+05$ \\
\hline 0.9 & $1.82 \mathrm{E}+05$ & $1.605 \mathrm{E}+05$ \\
\hline
\end{tabular}

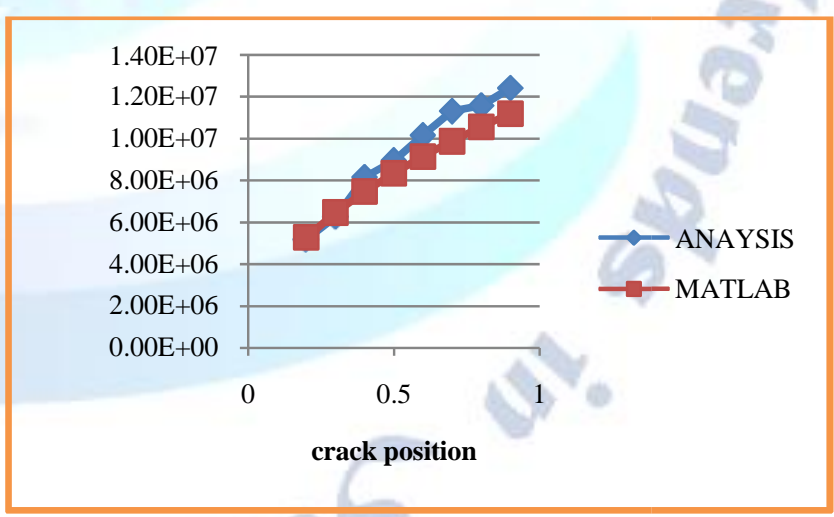

Graph 3: comparison between analysis and matlab under axial load.

The above graphshowsthe ansys andmatlabstress intensity readings atdifferent crack position. Here if the crack location increases, stress intensityvalue also increases. matlab and ansys results are having good agreementbetween axial load results. 


\begin{tabular}{|c|c|c|}
\hline $\mathrm{c} / \mathrm{d}$ & $\begin{array}{c}\text { ANSYS } \\
\mathrm{Pa}\end{array}$ & $\begin{array}{c}\text { MATLAB } \\
\text { Pa }\end{array}$ \\
\hline 0.2 & $0.971 \mathrm{E}+07$ & $1.055 \mathrm{E}+07$ \\
\hline 0.3 & $1.39 \mathrm{E}+07$ & $1.292 \mathrm{E}+07$ \\
\hline 0.4 & $1.51 \mathrm{E}+07$ & $1.492 \mathrm{E}+07$ \\
\hline 0.5 & $1.56 \mathrm{E}+07$ & $1.668 \mathrm{E}+07$ \\
\hline 0.6 & $1.99 \mathrm{E}+07$ & $1.827 \mathrm{E}+07$ \\
\hline 0.7 & $2.19 \mathrm{E}+07$ & $1.973 \mathrm{E}+07$ \\
\hline 0.8 & $2.38 \mathrm{E}+07$ & $2.110 \mathrm{E}+07$ \\
\hline 0.9 & $2.40 \mathrm{E}+07$ & $2.238 \mathrm{E}+07$ \\
\hline
\end{tabular}

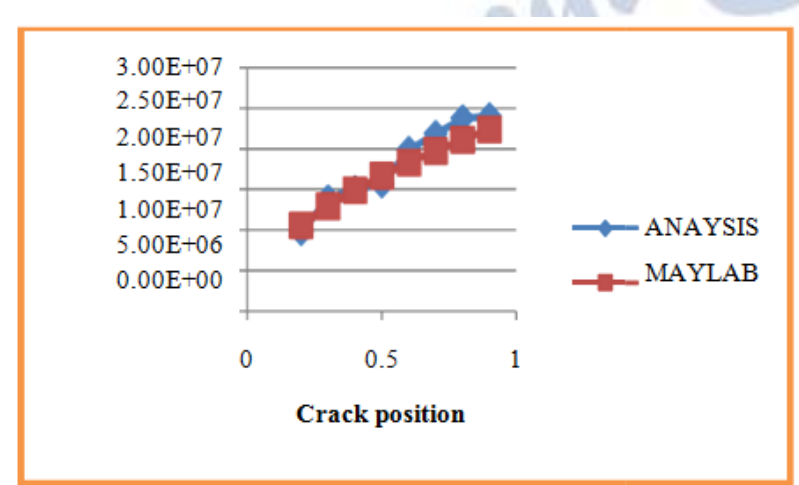

Graph4: Comparison between Ansys And Matlab Under Bending Load.

\begin{tabular}{|c|c|c|}
\hline$c / d$ & $\begin{array}{c}\text { ANSYS } \\
P a\end{array}$ & $\begin{array}{c}\text { MATLAB } \\
\text { Pa }\end{array}$ \\
\hline 0.2 & $5.18 \mathrm{E}+06$ & $5.27 \mathrm{E}+06$ \\
\hline 0.3 & $6.26 \mathrm{E}+06$ & $6.461 \mathrm{E}+06$ \\
\hline 0.4 & $8.16 \mathrm{E}+06$ & $7.460 \mathrm{E}+06$ \\
\hline 0.5 & $8.94 \mathrm{E}+06$ & $8.341 \mathrm{E}+06$ \\
\hline 0.6 & $1.01 \mathrm{E}+07$ & $0.913 \mathrm{E}+07$ \\
\hline 0.7 & $1.13 \mathrm{E}+07$ & $0.986 \mathrm{E}+07$ \\
\hline 0.8 & $1.16 \mathrm{E}+07$ & $1.055 \mathrm{E}+07$ \\
\hline 0.9 & $1.24 \mathrm{E}+07$ & $1.119 \mathrm{E}+07$ \\
\hline
\end{tabular}

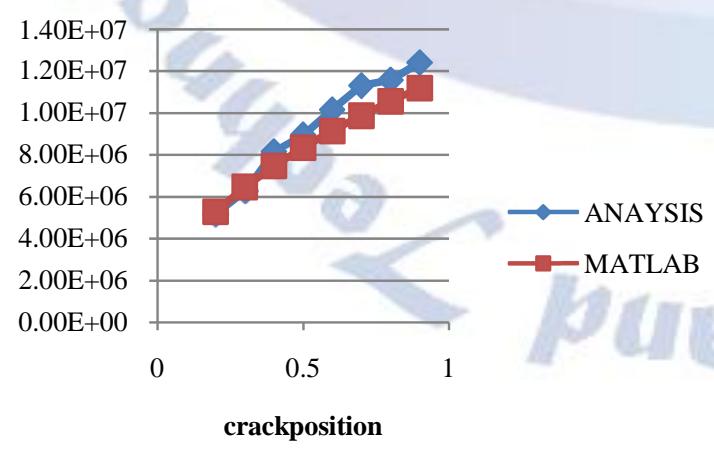

Graph5: Comparison between Ansys and matlab under torsion load.

\section{CONCLUSION}

From the observations the natural frequency with crack values are high at the center location of the propeller shaft at $0.45 \mathrm{~m}$ from the end the frequency value is $52.6541 \mathrm{~Hz}$ in ansys and $52.7406 \mathrm{~Hz}$ in matlab.In the axial load conditions it is observed that stress intensity value at 0.6 crack depth ratio is $1.3 \times 105$ Paand then the propeller shaft enters into plasticity state.

In the bending moment conditions it is observed that, at $0.3 \mathrm{crack}$ depth ratio $1.39 \times 107 \mathrm{~Pa}$ is the upper yield point and 0.4 crack depth ratio $1.51 \times 107 \mathrm{~Pa}$ is the lower yield point and then the propeller shaft entering into plasticity. In the torsional load conditions it is observed that 0.2 and 0.3 crack depth ratios the shaft is in under elastic behavior and at 0.3 crack depth ratio $6.62 \times 106 \mathrm{~Pa}$ is the upper yield point and 0.5 crack depth ratio $8.94 \times 106 \mathrm{~Pa}$ is the lower yield point and then the propeller shaft entering into plasticity. So many techniques are available to find out the locationof crack initation.inthisworkmainly concentratedon ashokLeylandheavy duty driveshaft. Wavelet method is used to identify the crack imitation by changing depth andposition. Mathematical model having good agreement natural frequency isproportional to stiffness of structural, if the stiffness reduces the crack can beinitiate. This method is implemented in drive shaft and location has found atmiddle of shaft. Is well as analysis has done on the crack propagation. For thisstudy the cracked shafts were subjected to axial, bending and torsional loadrespectively. These three sets of calculations were performed by using semianalytical method; the stress intensity factor of a cracked shaft was calculated by using the general equations obtained from the stress hand book. While numerical method, three sets of modeling under axial, bending, torsional load were modeled software successfully using FEA software Ansys by comparing results obtained semi analytically and numerically, the deviation in term of percentage had been found relatively small.If depth ratiois increased, the stress intensity ratio increases on axially, bending and torsion. Finally due to bending, we can see more changes.According to material maximum allowable stress intensity is $20 \mathrm{mpa}$ square root $\mathrm{m}$, and at 0.7 crack depth the stress intensity value had exceededthe $20 \mathrm{mpa}$ square root of $\mathrm{m}$. So by considering these studies o values we can estimate the damage detectionof driveshaft.

\section{REFERENCES}

[1] AndreaCarpinteri,"FatiguePropagationOfSurfaceFlawsIn Round Bars:A Three-Parameter Theoretical Model" fatigue fract, engng master, struct.Vol19, No12pp1471-1480,1996

[2] Aniket S. Kamble, D. S. Chavan, "Identification of crack parameters in a cantilever beam using experimental and 
wave let analysis”,International Journal on MechanicalEngineering and Robotics(IJMER),pp.23-27,2014.

[3] Marco A. Perez, Lluis Gil, Sergio Oler, "Impact damage identification in composit elaminates using vibration testing", Composite Structures108,pp.267-276,2014.

[4] P.K.Jena,D.N.Thatoi,J.Nanda,D.R.K.Parhi, “Effect of damage Parameters on vibration signatures of a cantilever beam", International Conference on Modelling, Optimisation and Computing (ICMOC 2012),pp.3318-3330,2012.

[5] KausharH.Barad,D.S.Sharma,VishalVyas,"Crackdetectioni n Cantilever beam by frequency based method", Nirma University International Conference on Engineering (NUiCONE),pp.770-775,2013

[6] Amit Banerjee, G Pohit, "Crack Investigation of Rotating Cantilever Beam by Fractal Dimension Analysis", International Conference on Innovations in Automation and Mechatronics Engineering, ICIAME,pp.88-195,2014.

[7] Journal of applied sciences"Stress Intensity Factor for Cracks Estimating from a Shaft " 11(10):1839-1844,2011 ISSN 1812-5654

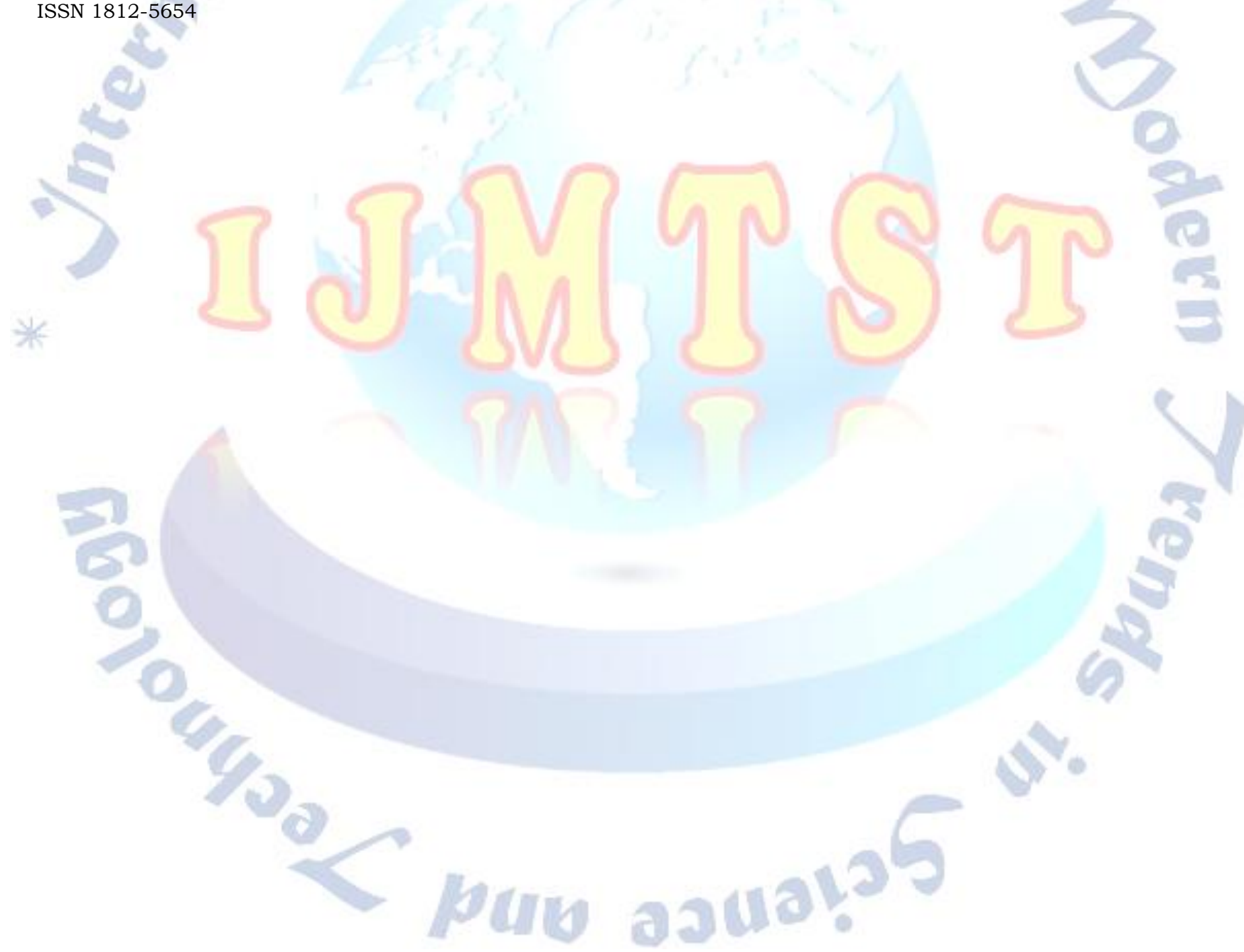

